\title{
Assessing clinical reasoning in undergraduate medical students during history taking with an empirically derived scale for clinical reasoning indicators
}

Sophie Fürstenberg ${ }^{1}$, Tillmann Helm¹, Sarah Prediger ${ }^{1}$, Martina Kadmon ${ }^{2}$, Pascal O. Berberat ${ }^{3}$ and Sigrid Harendza ${ }^{1 *}$

\begin{abstract}
Background: The clinical reasoning process, which requires biomedical knowledge, knowledge about problemsolving strategies, and knowledge about reasons for diagnostic procedures, is a key element of physicians' daily practice but difficult to assess. The aim of this study was to empirically develop a Clinical Reasoning IndicatorsHistory Taking-Scale (CRI-HT-S) and to assess the clinical reasoning ability of advanced medical students during a simulation involving history taking.

Methods: The Clinical Reasoning Indictors-History Taking-Scale (CRI-HT-S) including a 5-point Likert scale for assessment was designed from clinical reasoning indicators identified in a qualitative study in 2017. To assess indicators of clinical reasoning ability, 65 advanced medical students (semester 10, $n=25$ versus final year, $n=40$ ) from three medical schools participated in a 360-degree competence assessment in the role of beginning residents during a simulated first workday in hospital. This assessment included a consultation hour with five simulated patients which was videotaped. Videos of 325 patient consultations were assessed using the CRI-HT-S. A factor analysis was conducted and the students' results were compared according to their advancement in undergraduate medical training.

Results: The clinical reasoning indicators of the CRI-HT-S loaded on three factors relevant for clinical reasoning: 1) focusing questions, 2) creating context, and 3) securing information. Students reached significantly different scores $(p<.001)$ for the three factors (factor 1: $4.07 \pm .47$, factor $2: 3.72 \pm .43$, factor 3: $2.79 \pm .83$ ). Students in semester 10 reached significantly lower scores for factor 3 than students in their final year $(p<.05)$.

Conclusions: The newly developed CRI-HT-S worked well for quantitative assessment of clinical reasoning indicators during history taking. Its three-factored structure helped to explore different aspects of clinical reasoning. Whether the CRI-HT-S has the potential to be used as a scale in objective structured clinical examinations (OCSEs) or in workplacebased assessments of clinical reasoning has to be investigated in further studies with larger student cohorts.
\end{abstract}

Keywords: Assessment, Clinical reasoning, Competence, History taking, Medical education

\footnotetext{
* Correspondence: harendza@uke.de

'Department of Internal Medicine, University Medical Center

Hamburg-Eppendorf, III Medizinische Klinik, Martinistr. 52, D-20246 Hamburg,

Germany

Full list of author information is available at the end of the article
}

(c) The Author(s). 2020 Open Access This article is licensed under a Creative Commons Attribution 4.0 International License, which permits use, sharing, adaptation, distribution and reproduction in any medium or format, as long as you give appropriate credit to the original author(s) and the source, provide a link to the Creative Commons licence, and indicate if changes were made. The images or other third party material in this article are included in the article's Creative Commons licence, unless indicated otherwise in a credit line to the material. If material is not included in the article's Creative Commons licence and your intended use is not permitted by statutory regulation or exceeds the permitted use, you will need to obtain permission directly from the copyright holder. To view a copy of this licence, visit http://creativecommons.org/licenses/by/4.0/ The Creative Commons Public Domain Dedication waiver (http://creativecommons.org/publicdomain/zero/1.0/) applies to the data made available in this article, unless otherwise stated in a credit line to the data. 


\section{Background}

Clinical reasoning is a core element of medical practice. In medical experts, the thinking during a patient contact happens with the most likely diagnostic hypothesis being formed within the first minutes [1]. This hypothesis is confirmed, refined or ruled out as a result of further information through specific target-oriented questions [1]. While experts begin the clinical reasoning process by intuitively generating a list of hypotheses using their experiential knowledge [2], novices seem to consciously match patients' symptoms to the concepts they have memorized [3]. Additionally, contextual factors of patients' histories appear to have an impact on medical experts' clinical reasoning performance [4, 5]. Because some clinical reasoning skills are either subconscious or not fully articulated by clinicians [6] they are difficult to be taught [7] and often acquired in an informal rather than an explicit way, e.g. during clerkships or bedside teaching. After a patient encounter, the teacher often asks medical students only for a possible diagnosis and diagnostic tests leading to this diagnosis without considering the reasoning process itself [8].

Assessment of clinical reasoning is also challenging because it must be inferred from behaviour [9]. Different assessment strategies have been suggested $[9,10]$ and their combination is recommended to assess diagnostic accuracy with respect to different content and contexts [9]. We may have some clues to how novices articulate and enact clinical reasoning during history-taking based on qualitative observations by Haring et al. [11]. In their study, medical expert watched recorded medical students' history taking in patient encounters and discussed their discoveries whenever they felt clinical reasoning occurred [11]. These qualitatively identified clinical reasoning indicators consist of general and specific observable phenomena which include context factors and frames of reference incorporated by the assessors [12]. Furthermore, the experts also considered themselves as a reference for clinical reasoning, being able to observe how well students can engage in hypothesis directed data gathering during history taking [11]. This is in line with the social perception theory assuming that assessors use idiosyncratic pre-existing schemes based on expectations in the evaluation of students in a specific situation [13]. It is not fully understood how such internal frames or standards to assess clinical reasoning are developed [14].

Since Haring et al. identified indicators for clinical reasoning [11], the aim of our study was to develop an instrument that incorporates these expert-based indicators to assess medical students' clinical reasoning during simulated patient consultations in an attempt to standardize assessors' observations of clinical reasoning. The quality of this new instrument to assess medical students' clinical reasoning by observing their history taking was defined and the clinical reasoning ability of medical students of different advancement in their undergraduate studies was assessed.

\section{Methods}

To assess indicators of clinical reasoning ability advanced medical students participated in a 360-degree competence assessment in the role of beginning residents during a simulated first workday of residency [15]. This assessment, representing a high-fidelity simulation of a clinical environment, was based on selected competences relevant for beginning residents [16]. The assessment consisted of three phases: 1) a consultation hour with five simulated patients, 2) a management phase (2.5 h) to organize these patients' next diagnostic steps and to interact with other health care personnel, and 3) a handover of the patients to a resident $(30 \mathrm{~min})$. The consultation hour with five simulated patients covering five different contexts, namely a 42-year-old female with palpitations (patient 1), a 53-year-old male with fatigue and hemoptysis (patient 2), a 58-year-old female with abdominal pain (patient 3), a 54-year-old male with flank pain (patient 4), and a 36-year-old female with rheumatoid arthritis and fever (patient 5), as well as the handover were video-recorded. The patient cases were based on real patients and designed with elements of complexity that were intended to induce analytic thinking processes [17].

In 2018, Haring et al. identified 13 relevant items which were abstracted from students' observable behaviour during history taking by expert assessors in a qualitative study using a grounded theory approach [11]. We used eight of her original items, which were identified as clinical reasoning indicators and transformed them into a scale (Fig. 1), which we named Clinical Reasoning Indicators - History Taking Scale (CRI-HT-S). We included the following items, which describe student activities associated with language or language related behaviour and which can be quantitated: 1 . Taking the lead in the conversation, 2. Recognizing and responding to relevant information, 3. Specifying symptoms; 4. Asking specific questions that point to pathophysiologic thinking, 5. Putting questions in a logical order, 6. Checking with patient, 7. Summarizing, and 8. Data gathering and efficiency. The remaining five items, which did not meet these criteria, e.g. body language [11], were not included in the scale. Each included item was operationalized with a short description and could be rated on a 5-point Likert scale: 1 = does not meet the criterion at all, $2=$ rather does not meet the criterion, 3 = partly meets the criterion, $4=$ rather meets the criterion, and $5=$ fully meets the criterion. A maximum clinical reasoning ability sum score of 40 could be achieved for each individual conversation with one patient. Internal-rater reliability was scrutinized in a pilot by $\mathrm{TH}$ and $\mathrm{SH}$ assessing a sample 


\section{Clinical Reasoning Indicators - History Taking (CRI-HT)}

\begin{tabular}{|c|c|c|c|c|c|}
\hline Clinical reasoning indicators & 1 & 2 & 3 & 4 & 5 \\
\hline $\begin{array}{l}\text { 1. Taking the lead in the conversation } \\
\text { The student takes control of the interview in order to get the } \\
\text { required information. }\end{array}$ & 0 & 0 & 0 & 0 & 0 \\
\hline $\begin{array}{l}\text { 2. Recognizing and responding to relevant information } \\
\text { The student shows that s/he recognizes relevant information by } \\
\text { e.g. responding with obvious interest to them. }\end{array}$ & 0 & 0 & 0 & 0 & 0 \\
\hline $\begin{array}{l}\text { 3. Specifying symptoms } \\
\text { The student makes targeted inquiries to capture the symptoms in } \\
\text { more detail which s/he considers to be important. }\end{array}$ & 0 & 0 & 0 & 0 & 0 \\
\hline $\begin{array}{l}\text { 4. Asking specific questions that point to pathophysiological } \\
\text { thinking } \\
\text { The student's questions indicate that } s / \text { he is considering specific } \\
\text { causes for certain symptoms. }\end{array}$ & 0 & 0 & 0 & 0 & 0 \\
\hline $\begin{array}{l}\text { 5. Putting questions in a logical order } \\
\text { The student asks the questions in a logical order and not } \\
\text { according to a list. }\end{array}$ & 0 & 0 & 0 & 0 & 0 \\
\hline $\begin{array}{l}\text { 6. Checking with the patient } \\
\text { The student assures her-/himself by checking with the patient that } \\
\text { her/his clinical thinking is based on correct information. }\end{array}$ & 0 & 0 & 0 & 0 & 0 \\
\hline $\begin{array}{l}\text { 7. Summarizing } \\
\text { The student summarizes her/his collected information aloud as } \\
\text { soon as they have reached a meaningful level. }\end{array}$ & 0 & 0 & 0 & 0 & 0 \\
\hline $\begin{array}{l}\text { 8. Collected data and effectiveness of the conversation } \\
\text { The student collects sufficient, high quality data at reasonable } \\
\text { speed. }\end{array}$ & 0 & 0 & 0 & 0 & 0 \\
\hline
\end{tabular}

(1)

$\begin{array}{ccc}\begin{array}{c}\text { does not meet } \\ \text { the criterion }\end{array} \text { meet the criterion } & \text { partly meets } \\ \text { the criterion }\end{array}$

(4)

rather meets fully meets
the criterion $\quad$ the criterion

Fig. 1 Clinical Reasoning Indicators - History Taking - Scale (CRI-HT-S)

of 10 videos. The agreement per item for this pilot was set to $80.0 \%$. On this condition, an overall agreement for the evaluation of these 10 videos of .91 was reached between the two raters. Additionally, we calculated the intraclass correlation coefficient (ICC) for the whole questionnaire, which was .541 and can be described as "fair" [18]. The 325 videos were subsequently assessed by $\mathrm{TH}$ using this scale in a random and blinded order. The internal consistency (Cronbach's alpha) of the CRIHT-S in our study sample was .78. Because clinical reasoning is highly context specific, the Cronbach's alpha of the CRI-HT-S for the different patient cases were also calculated: patient $1=.70$, patient $2=.66$, patient $3=.63$, patient $4=.63$, and patient $5=.67$.

In July 2017, 70 advanced medical students (semester 10 to 12 , i.e. end of year five to end of year six of a sixyear undergraduate medical training) from three medical schools of different size and location (University
Hamburg, University Oldenburg, Technical University Munich) participated in the validated 360-degree assessment [17] which took place at the University Medical Center Hamburg-Eppendorf (UKE). The Technical University Munich provides a standard clinical curriculum following two years of pre-clinical studies. The universities Hamburg and Oldenburg teach medicine in vertically integrated courses with pre-clinical and clinical content being taught from year one. Neither of the universities teaches hypothesis-directed history taking or clinical reasoning. At the end of semester 10, students have finished all clinical rotations and afterwards, up to semester 12, students work full time on wards for a maximum of one year. Three students from Hamburg were excluded from the analysis because they had not reached their 10th semester. One student from Oldenburg and one student from Munich had to be excluded because of incomplete data sets. Eventually, data from 
65 students were analyzed: $n=35$ students from the University Medical Center Hamburg-Eppendorf, $n=5$ students from the Carl von Ossietzky University of Oldenburg, and $n=25$ students from the Technical University of Munich. Additionally, sociodemographic data of these 65 students (semester 10, $n=25$; final year, $n=$ 40) were collected. In total, 325 videos were obtained ( $n=125$ from semester 10 and $n=200$ from final year). This study is part of a larger study [19]. The Ethics Committee of the Chamber of Physicians (Ethik-Kommission, Ärztekammer Hamburg), Hamburg, confirmed the innocuousness of the study and its accordance with the Declaration of Helsinki. Participation was voluntary and anonymized and participants consented to their participation (reference number: PV3649).

A factor analysis was conducted for the items of the questionnaire, which resulted in three factors. For statistical analysis, the means $(M)$ of the different clinical reasoning indicators, of the three factors, and of the CRIHT-S sum scores of the complete scale were calculated, respectively, per group of participants. Bonferroni correction for multiple testing was applied when necessary. Cohen's d was calculated as measure for the effect size of significant differences. CRI-HT-S sum scores and means of the three factors were additionally calculated per patient and per group of participants. Statistical analysis included a two-way analysis of variance (ANOVA) to study differences between the groups of participants.

\section{Results}

Of the 65 participants, 25 medical students were in semester 10 (age: $25.5 \pm 2.2$ years), 40 students were in their final year of undergraduate medical training (age: $26.4 \pm 2.1$ years), 37 participants were female and 28 were male. Table 1 shows the rotated factor matrix with the eight clinical reasoning indicators loading on three factors. Factor 1 includes three items comprising aspects of "Focusing questions", factor 2 consists of three items, which depict "Creating context", and factor 3 includes two items, which indicate "Securing information". In
Table 2, the overall means for the eight individual CRIHT-S items and the three factors are shown, respectively. Means of all factors differ significantly $(p<.001)$ with factor 1 reaching the highest $(4.07 \pm .47)$ and factor 3 reaching the lowest mean score $(2.79 \pm .83)$. "Taking the lead in the conversation" was the individual item with the highest score $(4.36 \pm .42)$ while "Summarizing" reached the lowest score $(2.27 \pm .93)$. The total mean score for the complete CRI-HT-S including all eight items was $28.96 \pm 2.89$.

With respect to the sum scores reached for the five different patients no significant differences could be detected between the patients (Table 3). When the mean scores for the three different factors were compared between the five patients, we found significantly lower mean scores $(p \leq .001)$ for factor 1 in patient 1 compared to the other four patients, and for patient 2 (man with fatigue and hemoptysis) versus patient 3 (woman with abdominal pain) and 5 (woman with rheumatoid arthritis and fever). Students from semester 10 showed significantly lower overall scores with medium effect size for factor $3(p<.05$, $d=.69$ ) and both items of this factor compared with students in their final year (Table 4). Even though students from semester 10 reached slightly lower CRI-HT-S sum scores for the individual patients their scores did not differ significantly from the CRI-HT-S scores reached by final year students (10th semester versus final year: patient 1 : $26.16 \pm 4.73$ versus $27.22 \pm 3.69$; patient 2 : $26.72 \pm 4.21$ versus $29.07 \pm 3.00$; patient $3: 29.84 \pm 4.11$ versus $30.68 \pm$ 3.12; patient 4: $28.16 \pm 3.94$ versus $28.80 \pm 3.15$; patient 5 : $29.56 \pm 3.80$ versus $31.20 \pm 3.80$ ).

\section{Discussion}

Assessing clinical reasoning as part of the clinical reasoning process is an important but difficult task. Faculty members have different frames of reference when translating observations into judgements, high levels of inference can occur while observing students, and the way by which judgements are transferred into a numerical rating system can vary [12]. The instrument (CRI-HT-S),

Table 1 Rotated factor matrix with loadings

\begin{tabular}{lcc}
\hline Indicators of clinical reasoning ability & \multicolumn{2}{c}{ Factor } \\
\cline { 2 - 4 } & $\mathbf{1}$ & $\mathbf{2}$ \\
\hline Taking the lead in the conversation & .904 & .046 \\
Putting questions in a logical order & .751 & .375 \\
Specifying symptoms & .470 & .364 \\
Asking specific questions that point to pathophysiological thinking & .204 & .808 \\
Collected data and effectiveness & .071 & .740 \\
Recognizing and responding to relevant information & .530 & .597 \\
Summarizing & .037 & .024 \\
Checking with the patient & .217 & .168 \\
\hline
\end{tabular}


Table 2 Clinical reasoning ability of all participating students according to factors

\begin{tabular}{|c|c|c|c|}
\hline Indicators of clinical reasoning ability & $M \pm S D$ & $M \pm S D$ & Factor \\
\hline Taking the lead in the conversation & $4.36 \pm .42$ & $4.07 \pm .47 *$ & 1 \\
\hline Putting questions in a logical order & $4.00 \pm .47$ & & \\
\hline Specifying symptoms & $3.86 \pm .53$ & & \\
\hline Asking specific questions that point to pathophysiological thinking & $3.87 \pm .53$ & $3.72 \pm .43 *$ & 2 \\
\hline Collected data and effectiveness of the conversation & $3.62 \pm .34$ & & \\
\hline Recognizing and responding to relevant information & $3.67 \pm .43$ & & \\
\hline Summarizing & $2.27 \pm .93$ & $2.79 \pm .83 *$ & 3 \\
\hline Checking with the patient & $3.30 \pm .72$ & & \\
\hline
\end{tabular}
${ }^{*} p<.001$

which was developed from qualitatively identified clinical reasoning indicators [11] to assess clinical reasoning quantitatively during history taking, showed good internal consistency. This supports the use of the CRI-HT-S since clinical reasoning leads to the correct final diagnosis after history taking alone in 76.0\% [15]. In general, our participating students reached the highest scores in the CRIHT-S factor 1 ("Focusing questions") including the items "Taking the lead in the conversation", "Putting questions in a logical order", and "Specifying symptoms". We interpreted this as a sign that the students learned to apply specific patterns to organize patient information and relate it to their own knowledge in an expert way [20]. Rather than just applying a history taking scheme to their patient interviews the students were able to organize their history taking in a chief complaint driven way [21]. The item "Asking specific questions that point to pathophysiological thinking", which received the third-highest rating and belongs to factor 2 ("Creating context"), demonstrates that the students, like experts, were able to intuitively generate a list of diagnostic hypotheses to a certain extent and to test them by analytic reasoning [22]. "Summarizing", which is an important aspect of clinical reasoning during history taking to give the interviewer a chance to review the history for lack of clarity [23] was the only item with a score below satisfactory. Whether this relates to the way history taking is taught or is an effect of the time pressure students might have felt during the patient consultations remains to be investigated.
Students in their final year of undergraduate medial education showed significantly higher scores for factor 3 ("Securing information") and for its two items "Summarizing" and "Checking with the patient", respectively, than students from semester 10. This is an interesting finding which could reflect that medical students up to semester 10 are still taught history taking in the traditional way by obtaining the history in separate sequential categories (e.g. "history of the present illness", "past medical history", "review of systems" etc.) [24]. It has been shown over 40 years ago, that his method to teach history taking is deficient when used as the only teaching method [25]. The combination of content and process of history taking leads to better learning outcomes with respect to clinical reasoning $[26,27]$. Students in their final year have more learning opportunities with real history taking while working full time on hospital wards. Therefore, their learning is less static and rather resembles problem-based learning tutorials [28]. This might be a reason why they achieved higher scores for factor 3 in our study.

With respect to the different patients, the highest scores were reached for factor 1 when an illness script based on the presenting complaint could be easily developed (e.g. patient 3, a 58-year-old woman with abdominal pain in the left lower quadrant) during history taking by pattern recognition [29]. The development of illness scripts can already be fostered by case-based learning in the early years of a curriculum [30], which is

Table 3 Total sum scores of indicators of clinical reasoning and factors of clinical reasoning of all participating students per simulated patient

\begin{tabular}{|c|c|c|c|c|}
\hline Patient cases & $\begin{array}{c}\text { Sum score } \\
M \pm S D\end{array}$ & $\begin{array}{c}\text { Factor } 1 \\
M \pm S D\end{array}$ & $\begin{array}{c}\text { Factor } 2 \\
M \pm S D\end{array}$ & $\begin{array}{l}\text { Factor } 3 \\
M \pm S D\end{array}$ \\
\hline Patient 1: 42-year-old female with palpitations & $27.15 \pm 4.16$ & $3.55 \pm .67^{* * *}$ & $3.89 \pm .48^{*}$ & $2.42 \pm .90^{*}$ \\
\hline Patient 2: 53-year-old male with fatigue and hemoptysis & $28.17 \pm 3.67$ & $3.92 \pm .58^{* * *}$ & $3.73 \pm .54$ & $2.62 \pm .90^{*}$ \\
\hline Patient 3: 58-year-old female with abdominal pain & $30.35 \pm 3.52$ & $4.45 \pm .50^{* * *}$ & $3.68 \pm .46$ & $2.98 \pm .99$ \\
\hline Patient 4: 54-year-old male with flank pain & $28.55 \pm 3.46$ & $4.09 \pm .48^{* *}$ & $3.59 \pm .56$ & $2.76 \pm .85^{*}$ \\
\hline Patient 5: 36-year-old female with rheumatoid arthritis and fever & $30.57 \pm 3.85$ & $4.36 \pm .55$ & $3.72 \pm .47$ & $3.17 \pm 1.04$ \\
\hline
\end{tabular}

Factor 1: ${ }^{* *} p \leq .001$ : patient 1 versus patient $2,3,4$, and 5 ; patient 2 versus patient 3 and 5 , patient 3 versus patient $4 .{ }^{* *} p \leq .01$ : patient 4 versus patient 5 Factor 2: ${ }^{*} p<.05$ : patient 1 versus patient 3 and 4

Factor 3 : ${ }^{*} p<.05$ : patient 1 versus patient 3,4 and 5 ; patient 2 versus patient 3 and 5 ; patient 4 versus patient 5 
Table 4 Clinical reasoning ability of students from semester 10 and from the final year according to individual items and factors

\begin{tabular}{|c|c|c|c|c|c|c|}
\hline Indicators of clinical reasoning ability & $\begin{array}{c}\text { Semester } 10 \\
M \pm S D\end{array}$ & $\begin{array}{l}\text { Final Year } \\
M \pm S D\end{array}$ & $\begin{array}{l}\text { Semester } 10 \\
M \pm S D\end{array}$ & $\begin{array}{l}\text { Final Year } \\
M \pm S D\end{array}$ & $\begin{array}{l}\text { Cohen's } \\
\text { d }\end{array}$ & Factor \\
\hline Taking the lead in the conversation & $4.31 \pm .45$ & $4.39 \pm .40$ & $3.99 \pm .42$ & $4.12 \pm .36$ & .33 & 1 \\
\hline Putting questions in a logical order & $3.89 \pm .48$ & $4.07 \pm .46$ & & & & \\
\hline Specifying symptoms & $3.78 \pm .63$ & $3.92 \pm .46$ & & & & \\
\hline $\begin{array}{l}\text { Asking specific questions that point to } \\
\text { pathophysiological thinking }\end{array}$ & $3.77 \pm .61$ & $3.94 \pm .46$ & $3.69 \pm .39$ & $3.74 \pm .31$ & .14 & 2 \\
\hline Collected data and effectiveness of the conversation & $3.57 \pm .40$ & $3.65 \pm .30$ & & & & \\
\hline Recognizing and responding to relevant information & $3.74 \pm .42$ & $3.64 \pm .43$ & & & & \\
\hline Summarizing & $1.98 \pm .85^{*}$ & $2.46 \pm .94$ & $2.52 \pm .68^{*}$ & $2.96 \pm .74$ & .69 & 3 \\
\hline Checking with the patient & $3.06 \pm .71^{*}$ & $3.46 \pm .70$ & & & & \\
\hline
\end{tabular}

${ }^{*} p<.05$ : significantly different compared to final year

a standard didactic feature in undergraduate medical curricula [31]. Furthermore, the chief complaints of the patients in our study - palpitations, hemoptysis, abdominal pain, flank pain, and fever under immunosuppression, respectively, which are all learning objectives in the undergraduate curriculum - might have triggered clinical reasoning factors 1 ("Focusing questions") and 2 ("Creating context") with scores above 3.5 on a 5 -point scale. This might be due to a focus on the pathophysiology of diseases, i.e. their biomedical details, which play a greater role for learners than for experts who have seen more cases with experience and rely to a greater extent on pattern recognition to develop an illness script [32]. The patients with the chief complaints "abdominal pain" and "fever under immunosuppression" received the highest overall CRI-HT-S scores. This might be a hint that these medical conditions could have played a more prominent role [33] in undergraduate medical education.

Our empirically developed CRI-HT-S was not validated in a separate study by, e.g., comparing it with validated instruments for the assessment of reasoning or with the clinical reasoning outcomes of the participants in our assessment, which clearly represents a major weakness. However, the CRI-HT-S seems to be a tool with consistent performance in discriminating learners' clinical reasoning abilities across settings and shows an acceptable internal consistency of .78. The agreement between raters in a pilot test was .91 and ICC was "fair" (.541). However, it would have strengthened our study further, if a pilot test of the instrument had taken place with clinicians outside the team and if two to three raters had assessed all videos. Furthermore, different rater biases and aspects of rater variability have been described while assessing clinical skills, which e.g. include the raters' background knowledge and skills that will substantially shape their interpretation of others' behaviour $[34,35]$. This strongly indicates that the CRI-HT-S should be used with a rater training including aspects of rater biases and anchors to transfer possible observations of the different clinical reasoning indicators into a numerical scale to receive results with good internal consistency. Another weakness of the CRI-HT-S is that the items "Specifying symptoms" and "Recognizing and responding to relevant information" showed factor loadings below 0.6. However, both factors did not show higher loadings for another factor and their content fitted well with factor 1 and factor 2, respectively. Since we were only sampling a small subset of patient cases (i.e. context), our ability to make broad interpretations of medical knowledge is limited. On the other hand, we took care of balanced case difficulty during case design. The strengths of our study are the high number of rated videos and the participation of students from more than one university supporting the generalizability of our results. Furthermore, this is - to our knowledge - the first study with an operationalized scale which enables supervisors to quantitatively measure clinical reasoning indicators.

\section{Conclusion}

The empirically constructed CRI-HT-S could be applied with consistent performance and acceptable internal consistency to assess clinical reasoning indicators during history taking in videos of a simulated consulting hour with advanced medical students in the role of a beginning resident. Higher scores for the clinical reasoning factor "Creating context" could be observed in more advanced undergraduate medical students with longer clinical training. For patient cases, where an illness script could by easier developed, higher scores were achieved for the clinical reasoning factors "Focusing questions" and "Creating context". Whether the CRI-HT-S has potential to be used as a scale in objective structured clinical examinations or in workplace-based assessments of clinical reasoning has to be investigated in further studies with larger student cohorts. 


\section{Abbreviations}

CRI-HT-S: Clinical Reasoning Indicators- History Taking-Scale; ICC: Intraclass correlation coefficient; TUM: Technical University of Munich; UKE: University Medical Center Hamburg Eppendorf

\section{Acknowledgements}

We thank all medical students from the Universitätsklinikum HamburgEppendorf (UKE), from the Carl von Ossietzky University of Oldenburg, and from the TUM Medical Education Center who participated in this study.

\section{Authors' contributions}

$\mathrm{SH}, \mathrm{POB}$ and MK designed the study. TH and SH coordinated the study and the data acquisition. SF and SP performed the statistical analyses. SF and SH drafted the manuscript. TH, SP, POB, and MK revised the manuscript for important intellectual content. All authors read and approved the final manuscript.

\section{Funding}

This study has been developed as part of the project $\ddot{\mathrm{K} K H O M}$, which is funded by the German Ministry of Education and Research (BMBF), reference number: 01PK1501A/B/C. The funding body had no role in the design of the study, collection, analysis and interpretation of data and in writing the manuscript.

\section{Availability of data and materials}

All data and materials are available in the manuscript and can be obtained from the corresponding author upon request.

\section{Ethics approval and consent to participate}

The study was performed in accordance with the Declaration of Helsinki and the Ethics Committee of the Chamber of Physicians (Ethik-Kommission, Ärztekammer Hamburg), Hamburg, approved this study and confirmed its innocuousness. The study included written consent by the participants and participation was voluntary and anonymized (reference number: PV3649).

\section{Consent for publication}

Not applicable.

\section{Competing interests}

$\mathrm{SH}$ is section editor and MK is associate editor to BMC Medical Education. SF, $\mathrm{SP}, \mathrm{TH}$ and $\mathrm{POB}$ declare that they have no competing interests.

\section{Author details}

'Department of Internal Medicine, University Medical Center Hamburg-Eppendorf, III Medizinische Klinik, Martinistr. 52, D-20246 Hamburg, Germany. ${ }^{2}$ Faculty of Medicine, University of Augsburg, Deanery, Augsburg, Germany. ${ }^{3}$ TUM Medical Education Center, School of Medicine, Technical University of Munich, Munich, Germany.

\section{Received: 28 November 2019 Accepted: 28 September 2020}

\section{Published online: 19 October 2020}

\section{References}

1. Coderre S, Mandin H, Harasym PH, Fick GH. Diagnostic reasoning strategies and diagnostic success. Med Educ. 2003;37:695-703.

2. Brush JE Jr, Sherbino J, Norman GR. How expert clinicans intuitively recognize a medical diagnosis. Am J Med. 2017;130:629-364.

3. Charlin B, Boshuizen HPA, Custers DJ, Feltovich PJ. Scripts and clinical reasoning. Med Educ. 2007:41:1178-84.

4. Durning S, Artino AR Jr, Pangaro L, van der Vleuten CP, Schuwirth L. Context and clinical reasoning: understanding the perspective of the expert's voice. Med Educ. 2011:45:927-398.

5. Durning SJ, Artino AR, Boulet JR, Dorrance K, van der Vleuten C, Schuwirth $\mathrm{L}$. The impact of selected contextual factors on experts' clinical reasoning performance (does context impact clinical reasoning performance in experts?). Adv Health Sci Educ Theaory Pract. 2012;17:65-79.

6. Vanstone M, Monteiro S, Colvin E, Norman G, Sherbino J, Sibbald M, et al. Experienced physician descriptions of intuition in clinical reasoning: a typology. Diagnosis (Berl). 2019;6:259-68.

7. Cutrer WB, Sullivan WM, Fleming AE. Educational strategies for imporving clinical reasoning. Curr Probl Pediatr Adolesc Health Care. 2013;43:248-57.

8. Bowen لـL Educational strategies to promote clinical reasoning. $\mathrm{N}$ Engl J Med. 2006;355:2217-25.
9. Ilgen JS, Humberg AJ, Kuhn G, Hansen ML, Norman GR, Eva KW, et al. Assessing diagnostic reasoning: a consensus statement summarizing theory, practice, and future needs. Acad Emerg Med. 2012;19:1454-61.

10. Gruppen LD. Clinical reasoning: defining it, teaching it, assessing it. Studying It West J Emerg Med. 2017;18:4-7.

11. Haring CM, Cools BM, van Gurp PJM, van der Meer JWM, Postma CT. Observable phenomena that reveal medical students' clinical reasoning ability during expert assessment of their history taking: a qualitative study. BMC Med Educ. 2017;17:147.

12. Kogan JR, Conforti L, Bernabeo E, lobst W, Holmboe E. Opening the black box of clinical skills assessment via observation: a conceptual model. Med Educ. 2011:45:1048-60.

13. Govaerts MJ, Van de Wiel MW, Schuwirth LW, Van der Vleuten CP, Muitjens AM. Workplace-based assessment: raters' performance theories and constructs. Adv Health Sci Educ Theory Pract. 2013;18:357-96.

14. Lineberry M, Homos E, Pleguezuelos E, Mella J, Brailovsky C, Bordage G. Experts' responses in script concordance tests: a response process validity inverstiagation. Med Educ. 2019;53:710-22.

15. Harendza S, Berberat PO, Kadmon M. Assessing competences in medical students with a newly designed 360-degree examination of a simulated first day of residency: a feasibility study. J Community Med Health Educ. 2017;7:4.

16. Fürstenberg S, Schick K, Deppermann J, Prediger S, Berberat PO, Kadmon M, et al. Competencies for first year residents - physicians' views from medical schools with different undergraduate curricula. BMC Med Educ. 2017;17:154

17. Prediger S, Schick K, Fincke F, Fürstenberg S, Oubaid V, Kadmon M, et al. Validation of a competence-based assessment of medical students' performance in the physicians's role. BMC Med Educ. 2020;20:6.

18. Cicchetti DV. Guidelines, criteria, and rules of thumb for evaluating normed and standardized assessment instruments in psychology. Psychol Assess. 1994;6:284-90.

19. Peterson MC, Holbrook JH, Von Hales D, Smith NL, Staker LV. Contributions of the history, physical examination, and laboratory investigation in making medical diagnoses. West J Med. 1992;156:163-5.

20. Bordage $G$, Lemieux M. Semantic structures and diagnostic thinking of experts and novices. Acad Med. 1991:66:70-2.

21. Nierenberg R. The chief complaint driven medical history: implications for medical education. Int J Med Educ. 2017:8:205-6.

22. Jacoby LL. A process dissocitation framework: separating automatic from intentional uses of memory. J Mem Lang. 1991;30:513-41.

23. Lichtenstein PR. The medical interview. In: Walker HK, Hall WD, Hurst JW, editors. Clinical methods: the history, physical, and laboratory examinations. 3rd edtition. Boston: Butterworths; 1990. p. 29-36.

24. Pfeiffer C, Madray H, Ardolino A, Willms J. The rise and fall of students' skill in obtaining medical history. Med Educ. 1998;32:283-8.

25. Maquire GP, Rutter DR. History-taking for medical students. I-Deficiencies in performance Lancet. 1976:2:556-8.

26. Kurtz S, Silverman J, Benson J, Draper J. Marrying content and process in clinical method teaching: enhancing the Calgary-Cambridge guides. Acad Med. 2003;78:802-9.

27. Harendza S, Krenz I, Kinge A, Wendt U, Janneck M, et al. GMS J Med Educ. 2017;34:Doc66

28. Epstein RJ. Learning from the problems of problem-based learning. BMC Med Educa. 2004:4:1

29. Norman G, Monteiro S, Sherbino J. Is clinical cognition binary or continous? Acad Med. 2013:88:1058-60

30. Keemink Y, Custers EJFM, van Dijk S, Ten Cate O. Illness script development in pre-clinical education through case-based clinical reasoning training. Int $J$ Med Educ. 2018;9:35-41

31. Thistlethwaite JE, Davies D, Ekeocha S, Kidd JM, MacDougall C, Matthews $P$, et al. The effectiveness of case-based learning in health professional education. A BEME systematic review: BEME guide no. 23. Med Teach. 2012;34:e421-44.

32. Patel VL, Evans DA, Kaufman DR. Reasoning strategies and the use of biomedical knowledge by medical students. Med Educ. 1990;24:129-36.

33. Young $M$, Brooks $L$, Norman G. Found in translation: the impact of familiar symptom descriptions on diagnosis in novices. Med Educ. 2007:41:1146-51.

34. Gingerich A, Kogan J, Yeates P, Goevaerts M, Holmboe E. Seeing the 'black box' differently: assessor cognition from three research perspectives. Med Educ. 2014:48:1055-68.

35. Kogan JR, Hess BJ, Conforti LN, Holmboe ES. What drives faculty ratings of residents' clinical skills? The impact of faculty's own clinical skills. Acad Med. 2010;85(10 Suppl):S25-8

\section{Publisher's Note}

Springer Nature remains neutral with regard to jurisdictional claims in published maps and institutional affiliations. 